\title{
LULA NA VEJA: UMA REPRESENTAÇÃO MULTIMODAL DO DISCURSO DO MEDO
}

\author{
(Lula in Veja magazine: a multimodal representation of the \\ discourse of fear)
}

Alessandra Coutinho Fernandes ${ }^{1}$

\begin{abstract}
In this article, I offer a critical discourse analysis of the cover of the issue 1752 of Veja magazine based on resources of the Grammar of Visual Design. The cover analyzed here is the first of the seventeen Veja covers that compose one of the corpora of my PHD thesis, in which I investigate how Veja represented Lula from 2002 to 2006. My analysis shows that Veja materialized the discourse of fear both visually and verbally in its first representation of Lula's political trajectory as one of the candidates to the presidency of Brazil in 2002.
\end{abstract}

Keywords: Lula, Veja magazine, critical discourse analysis, grammar of visual design.

\section{RESUMO}

Neste artigo, faço uma análise de discurso crítica da capa da edição 1752 da Veja, com base em recursos fornecidos pela Gramática do Design Visual. A capa analisada é a primeira das dezessete capas da Veja que compõem um dos corpora de minha tese de doutorado, em que investigo como a Veja representou Lula de 2002 a 2006. Minha análise demonstra que a Veja

1. Docente do curso de Letras da Universidade Federal do Paraná. Doutora em Estudos Linguísticos - Análise de Discurso, UFPR. Mestre em Língua inglesa e literatura correspondente, UFSC. Lecionou inglês em escolas de línguas, tendo coordenado uma delas durante quatro anos. Foi docente da Faculdade Internacional de Curitiba, onde se dedicou tanto ao ensino presencial quanto ao ensino a distância e à pós-graduação (especialização). Áreas de interesse: Análise de Discurso Crítica, gêneros textuais, EFL. 
materializou o discurso do medo, tanto visualmente quanto verbalmente, em sua primeira representação da trajetória política de Lula como um dos candidatos à presidência do Brasil na campanha eleitoral de 2002.

Palavras-chave: Lula, revista Veja, análise de discurso crítica, gramática do design visual.

\section{Introdução}

Em minha tese de doutorado, analisei como a revista Veja representou Lula, em sua trajetória política, de 2002 a 2006. Meu corpus foi composto por dezessete edições da revista, nas quais investiguei tanto as capas que traziam a imagem de Lula quanto as reportagens a que se referiam as manchetes de capa sobre Lula. Este artigo apresenta a análise da primeira capa que compõe o corpus de minha tese. Meu objetivo aqui é poder demonstrar o potencial analítico que a Análise de Discurso Crítica, juntamente com os recursos fornecidos pela Gramática do Design Visual de Kress e van Leeuwen (2006), podem fornecer para a análise de textos midiáticos multimodais, como é o caso das capas de revistas.

\section{Mídia e poder}

Nas sociedades contemporâneas, os produtos da mídia circulam nos mais diferentes contextos - próximos ou fisicamente distantes de onde foram produzidos. Considerando que a matéria bruta dos produtos da mídia é a linguagem, seja ela verbal, visual, ou multimodal; e que falar em linguagem é falar em semiose - o que pressupõe a construção de significados; considerando também que, de acordo com o linguista britânico Norman Fairclough, usar a linguagem é uma forma de prática social, não podemos ingenuamente supor que o uso da linguagem pelos meios de comunicação de massa seja despreocupado, aleatório, ou livre de propósitos específicos. $\mathrm{Na}$ atual fase da modernidade, o uso da linguagem é mais do que nunca 
uma forma de se atingir objetivos não apenas pessoais, mas também de ordem política e econômica.

Os meios de comunicação detêm grande poder simbólico nas sociedades contemporâneas. Cuidadosamente produzidos, os produtos da mídia podem ter efeito sobre nossas crenças a respeito dos fatos do cotidiano, muitas vezes afetando nossas tomadas de decisões. Como 'detentoras de conhecimento', as instituições da mídia acabam por projetar relações de poder desiguais com aqueles/ as que consomem seus produtos, e que, portanto, "dependem" do conteúdo simbólico que elas disponibilizam. Entretanto, pode-se dizer que um aspecto ainda mais sério na relação da mídia com a sociedade é o desconhecimento de grande parte dos/as consumidores/ as de produtos midiáticos de que os 'fatos' veiculados pela mídia nada mais são do que representações da 'realidade', muitas vezes ideologicamente motivadas para apresentar o mundo e as pessoas de uma determinada forma e não de outra, a depender dos interesses das instituições que os veiculam. Nesse sentido, uma perspectiva crítica de abordagem da mídia tem muito a contribuir, em primeiro lugar, com a desmistificação das tão propagadas neutralidade e imparcialidade da mídia; e, em segundo lugar, com a 'desnaturalização' das maneiras como as pessoas, os eventos e os fatos do mundo físico e mental são representados pela mídia.

Quando Fairclough (1995) afirma que o poder da mídia é em grande parte uma questão linguística, ele não deixa de reconhecer que tal poder não advém unicamente do uso da linguagem. Entretanto, não se pode negar que a prática midiática é essencialmente discursiva, e como falar em prática pressupõe ação, subentende-se que a ação da mídia se dá primordialmente via linguagem, via discurso.

Essa ideia é corroborada por Thompson (2009a), que ao utilizar a noção de "campos de interação", inspirada no conceito de 'campo' de Bourdieu (1990), correlaciona comunicação - enquanto forma de agir no mundo - e poder. ${ }^{2}$ Seu ponto de partida é a hipótese de que

2. Definição de campo em "A dissolução do religioso" In: Pierre Bourdieu. Coisas ditas. São Paulo, Brasiliense, 1990: 119: "um espaço - o que eu chamaria de campo - no interior do qual há uma luta pela imposição da definição do jogo e dos trunfos 
"se comunicação é uma forma de ação, a análise da comunicação deve se basear, pelo menos em parte, na análise da ação e na consideração de seu caráter socialmente contextualizado" (Thompson, 2009a: 20). Segundo Thompson, enquanto membros de uma sociedade, os indivíduos agem intencionalmente dentro de contextos sociais estruturados com o objetivo de atingir objetivos diversos.

A ação dos indivíduos na sociedade não é, contudo, totalmente livre. Ela está condicionada, como Thompson afirma, aos diferentes recursos que são disponibilizados heterogeneamente aos indivíduos dentro de campos de interação:

Os indivíduos se situam em diferentes posições dentro destes campos, dependendo do tipo e da quantidade de recursos disponíveis para eles. Em alguns casos estas posições, quando institucionalizadas, adquirem uma certa estabilidade - isto é, tornam-se parte de um conjunto relativamente estável de regras, recursos e relações sociais (...) A posição que um indivíduo ocupa dentro de um campo ou instituição é muito estreitamente ligada ao poder que ele ou ela possui. (Thompson, 2009a: 21)

A citação acima demonstra que há uma inter-relação entre recursos e poder dentro dos campos de interação. Em instituições, ou contextos sociais estruturados - a escola, a igreja, a família, a empresa, a mídia etc. - quanto mais recursos para atingir seus objetivos os indivíduos possuam, mais poderosos eles se tornam.

No que concerne à definição de poder, Thompson (2009a: 21) afirma usar o termo de modo genérico, entendendo-o como "um fenômeno social penetrante, característico de diferentes tipos de ação e de encontro, desde as ações reconhecidamente políticas dos funcionários públicos até os encontros mais prosaicos entre indivíduos na rua”. Quanto aos tipos de poder, Thompson reconhece quatro deles, a saber: "econômico", "político", "coercitivo" e "simbólico". Muito resumidamente, podemos dizer que o poder econômico provém da transformação de matéria-prima em bens de consumo; o poder

necessários para dominar nesse jogo”. Disponível em: http://www.opandeiro.net/ cursos/apostilas/teoria/bourdieu_campo.pdf. Acesso em: 25/11/2010. 
político, da coordenação dos indivíduos e da regulamentação das interações humanas; o poder coercitivo, da força; e o poder simbólico, da produção, transmissão e recepção do significado das formas simbólicas.

No quadro abaixo, podemos ver como as formas de poder estão correlacionadas a recursos, e em quais instituições elas podem ser mais facilmente identificadas:

\section{Quadro 1 - Formas de poder}

\begin{tabular}{|c|c|c|}
\hline Formas de poder & Recursos & Instituições paradigmáticas \\
\hline Poder econômico & $\begin{array}{l}\text { Materiais e } \\
\text { financeiros }\end{array}$ & $\begin{array}{c}\text { Instituições econômicas } \\
\text { (p.ex. empresas comerciais) }\end{array}$ \\
\hline Poder político & Autoridade & Instituições políticas (p.ex. estados) \\
\hline $\begin{array}{l}\text { Poder coercitivo } \\
\text { (especialmente } \\
\text { poder militar) }\end{array}$ & Força física e armada & $\begin{array}{l}\text { Instituições coercitivas (especialmente } \\
\text { militares, mas também a polícia, institui- } \\
\text { ções carcerárias, etc.) }\end{array}$ \\
\hline Poder simbólico & $\begin{array}{l}\text { Meios de } \\
\text { informação e comu- } \\
\text { nicação }\end{array}$ & $\begin{array}{c}\text { Instituições culturais (p.ex. igrejas, } \\
\text { escolas e universidades, as indústrias da } \\
\text { mídia, etc.) }\end{array}$ \\
\hline
\end{tabular}

Fonte: Thompson, 2009a, p. 25.

O poder da indústria da mídia é identificado como sendo um poder simbólico. Porém, isso não significa que outras formas de poder - tais como o poder econômico e o poder político, por exemplo, não estejam presentes nas indústrias da mídia. Thompson (2009a: 24) afirma que essas quatro formas de poder "comumente se sobrepõem de maneiras complexas e variadas". Entretanto, não se pode negar que o poder das instituições culturais é simbólico em sua essência. Segundo Thompson, esse poder atravessa constantemente a experiência social dos indivíduos, que 
são continuamente envolvidos na comunicação uns com os outros e na troca de informações de conteúdo simbólico. Assim fazendo, se servem de toda sorte de recursos que descreverei como "meios de informação e comunicação". Estes recursos incluem os meios técnicos de fixação e transmissão; as habilidades, competências e formas de conhecimento empregadas na produção, transmissão e recepção da informação e do conteúdo simbólico (que Bourdieu chama de "capital cultural"); e o prestígio acumulado, o reconhecimento e o respeito tributados a alguns produtores ou instituições ("capital simbólico"). (Thompson, ibid)

Um aspecto relevante no que concerne à relação entre mídia e poder diz respeito às relações assimétricas que se estabelecem entre produtores/as e consumidores/as da mídia, uma vez que os recursos de codificação disponíveis aos/às produtores/as de mídia são normalmente bem mais vastos do que aqueles disponíveis aos/às consumidores/as desses produtos. Essa assimetria ocorre em grande parte em decorrência do uso que os/as produtores/as de mídia fazem dos meios técnicos no processo de codificação do conteúdo simbólico. ${ }^{3}$ Segundo Thompson (2009a: 29),

os indivíduos que empregam um meio, devem conhecer, até certo ponto, as regras e os procedimentos. $\mathrm{O}$ domínio destas regras e procedimentos não exige necessariamente a capacidade de os formular de modo claro e explícito, apenas a habilidade de usá-los na prática (...)

Posteriormente, em meu exercício de análise de uma capa da Veja, utilizarei o aparato teórico-metodológico fornecido pela Gramática do Design Visual de Kress e van Leewen (2006). Essa gramática traz um tal nível de detalhamento de recursos para se analisar a composição de textos multimodais que quem não é estudioso/a da área de mídia ou de linguagem pode duvidar que tantos aspectos possam ser usados conscientemente durante a

3. Segundo Thompson (2009a: 26), "Na produção de formas simbólicas e na sua transmissão para os outros, os indivíduos geralmente empregam um meio técnico. O meio técnico é o substrato material das formas simbólicas, isto é, o elemento material com que, ou por meio do qual, a informação ou o conteúdo simbólico é fixado e transmitido do produtor para o receptor". 
produção de uma capa de revista, por exemplo. Entretanto, como a citação acima ressalta, os indivíduos responsáveis por empregar um meio técnico específico precisam ter algum conhecimento sobre o uso de regras e procedimentos relacionados ao meio escolhido. Esse conhecimento, mesmo que intuitivo, é essencial para a codificação eficiente do conteúdo simbólico. Sendo assim, é de se esperar que as capas da Veja não sejam o produto da composição de textos multimodais aleatórios, mas de textos altamente tecnologizados.

Possuir habilidades e competências para decodificar os conteúdos simbólicos codificados nos meios técnicos de comunicação é uma forma de os/as consumidores/as diminuírem a lacuna de conhecimento que os/as separam dos/as produtores/as de produtos midiáticos. Embora, como Thompson afirma, as habilidades e competências utilizadas pelos/as consumidores/as das formas simbólicas não sejam necessariamente as mesmas utilizadas pelos/ as codificadores/as dessas formas, os/as consumidores/as precisam elencar uma série de conhecimentos e suposições que os/as ajudarão a decodificar qualquer mensagem.

\section{Fundamentação teórica: Análise de Discurso Crítica e Gramática do Design Visual}

Para investigar como as instituições da mídia produzem sentidos a partir das representações que materializam, tomo como base a versão de Análise de Discurso Crítica (ADC) proposta pelo linguista britânico Norman Fairclough e a Gramática do Design Visual de Kress e van Leeuwen (2006).

\subsection{A versão de Análise de Discurso Crítica de Fairclough}

Em Discourse in late modernity, Chouliaraki e Fairclough (1999) empreendem uma mudança da concepção de discurso como 
"prática social" para a concepção de discurso como "parte irredutível da vida social, dialeticamente interconectada a outros elementos da vida social”.

Ao utilizar a expressão 'prática social', a ADC articula o conceito de 'prática social' adotado no Realismo Crítico, que concebe a dimensão das práticas sociais como o ponto de conexão que une estruturas abstratas e eventos concretos, e o conceito de 'prática social' proposto por Harvey (1996), que vê as práticas sociais como compostas por diversos elementos da vida:

Uma determinada prática integra diferentes elementos da vida em formas e relacionamentos locais específicos - tipos específicos de atividades, conectadas de maneiras específicas a materiais específicos e locações espaços-temporais específicas; pessoas específicas com experiências, conhecimentos e disposições específicas em relações sociais específicas; recursos semióticos específicos e maneiras de usar a linguagem específicas; e assim por diante. (Chouliaraki e Fairclough, 1999: 21)

Na concepção de Harvey (1996), os diversos elementos da vida constituem os diferentes momentos das práticas sociais. Em Analysing Discourse, Fairclough (2003: 25) identifica cinco momentos das práticas sociais, mais ou menos articulados entre si. São eles: ação e interação, relações sociais, pessoas (com crenças, valores, atitudes, histórias), mundo material e discurso. Esses momentos relacionamse dialeticamente dentro das práticas de forma que cada um deles “'internaliza' os outros sem se reduzir aos outros” (ibid).

Nesse nível intermediário das práticas sociais, a linguagem figura como 'ordens de discurso' - a faceta discursiva das práticas sociais, que determina a diferenciação e a variação linguística. ${ }^{4}$ Quando dizemos, portanto, que a ADC focaliza o nível intermediário

4. O termo 'ordem de discurso' foi cunhado por Foucault (1971). Contudo, é utilizado na ADC não tanto em seu sentido original, como agrupamento de discursos que circulam em contextos sociais específicos, mas "como a estruturação social da variação linguística ou diferença - há sempre muitas possibilidades diferentes na linguagem, mas a escolha de uma delas é socialmente estruturada". (Fairclough, 2003: 220) 
entre o que o sistema linguístico possibilita e o que é materializado nos textos, o que está implicado é que a ADC se preocupa em investigar o relacionamento dialético dos elementos das ordens de discurso com outros momentos não-discursivos das práticas sociais.

Conforme Fairclough (2003: 24), "os elementos de ordens de discurso não são coisas como substantivos e sentenças (elementos das estruturas linguísticas), mas discursos, gêneros e estilos...”. O autor (2003: 24-25) também ressalta que esses elementos das ordens de discurso "não são categorias puramente linguísticas, mas categorias que atravessam a divisão entre linguagem e 'não-linguagem', o discursivo e o não-discursivo”. Um aspecto importante dos elementos das redes de discurso é que da mesma forma que os diversos estratos do sistema linguístico constituem redes de opções limitando e possibilitando as escolhas dos/as usuários/as de uma língua; no nível das ordens de discurso, são os discursos, os gêneros e os estilos que constituem redes de opções. A maneira como gêneros, discursos e estilos se combinam compõe arranjos relativamente duráveis de práticas discursivas.

Nas ordens de discurso, a linguagem figura de três maneiras principais: como formas de ação, como formas de representação e como formas de ser (Fairclough, 2003). Essas três maneiras através das quais o momento discursivo se organiza nas práticas sociais são materializadas em textos e representadas por gêneros, discursos e estilos - respectivamente. Em outras palavras, utilizando textos (orais, escritos, multimodais), agimos discursivamente por meio de gêneros; representamos o mundo material, as pessoas, valores, crenças, usando discursos para "falar" a partir de determinadas perspectivas; e construímos nossas identidades, nossas maneiras de ser parcialmente através do discurso. ${ }^{5}$

Segundo Fairclough (2003), quando analisamos textos a partir de uma perspectiva multifuncional, como a Linguística Sistêmica Funcional (LSF) faz, por exemplo, percebemos os textos como

5. Fairclough (2003: 3-4), a propósito, utiliza o termo discurso em dois sentidos: tanto abstratamente, significando semiose em geral, quanto mais concretamente, como substantivo contável, significando "maneiras específicas de representar partes do mundo" - por exemplo, o discurso midiático da Veja. 
simultaneamente representando aspectos do mundo e estabelecendo relações sociais entre os/as participantes interativos, de uma maneira coerente e coesa. Em sua proposta transdisciplinar, a ADC adota a visão multifuncional de textos da LSF, reformulando-a de forma a incorporar os elementos das ordens de discurso nos textos. Sendo assim, com o objetivo de integrar o estudo de textos ao seu aparato teórico-metodológico baseado no Realismo Crítico, em vez de afirmar que os textos têm três funções simultâneas, a ADC afirma que não apenas os textos completos, mas também os excertos de textos colocam em prática três tipos de significados, a saber: o significado acional, o significado representacional e o significado identificacional. Como Resende e Ramalho (2006: 61) afirmam: "Gêneros, discursos e estilos ligam o texto a outros elementos da esfera social - as relações internas do texto a suas relações externas -, por isso a operacionalização desses conceitos mantém o cerne do pensamento de Halliday".

Um aspecto relevante no que concerne aos três significados textuais diz respeito ao fato de eles ocorrerem dialeticamente nos textos. Por exemplo, o discurso neoliberal pode ser utilizado em uma matéria jornalística, na tentativa de buscar uma identificação dos/ as leitores/as dessa matéria com os pressupostos do neoliberalismo. Nesse exemplo temos, então, um discurso - o discurso neoliberal, um gênero - a matéria jornalística, e uma forma de identificação - a identificação dos/as leitores/as com os pressupostos do neoliberalismo, entrelaçados na prática discursiva midiática.

Como Fairclough (2003: 29) afirma, baseado em Harvey (1996), de certa forma, cada um dos significados textuais internaliza os outros. Entretanto, nada impede que, para fins de pesquisa, decidase focar na relação de apenas um, ou dois, dos elementos das ordens de discurso com seu/s respectivo/s significado/s textual/ais. Na análise da capa da edição 1752 da Veja, que apresento neste artigo, posso dizer que meu foco está no significado representacional, pois me preocupo em analisar como a Veja representa Lula naquela capa, observando como a revista constrói o discurso do medo de forma a, potencialmente, desfavorecer Lula na campanha presidencial de 2002. 


\subsection{A Gramática do Design Visual como instrumento de análise de gêneros multimodais}

Quando Kress e van Leeuwen (2006) propuseram sua Gramática do Design Visual, eles tinham consciência de que não eram os primeiros a enveredar pelos caminhos da semiótica visual. Entretanto, haviam percebido que os estudos de imagens feitos até então tinham como ênfase principal o que seria o "léxico" das imagens, ou seja, o aspecto conotativo e denotativo das imagens - as pessoas, lugares e coisas representadas na imagem. Não havia, por assim dizer, um foco na "gramática", na "sintaxe" das imagens, ou seja, na forma como os vários elementos de uma imagem se combinam para formar um todo coerente.

Com relação à carga semântica da palavra 'gramática' como um conjunto autoritário de regras a serem seguidas, Kress e van Leeuwen (ibid) esclarecem que a escolha pela palavra 'gramática' no título Reading images: the grammar of visual design deve ser compreendida na perspectiva social proposta por Michael Halliday, em que "as formas gramaticais são fontes para codificar interpretações de experiências e formas de (inter) ação social” (Kress \& van Leeuwen, 2006: 1). Segundo os autores, as estruturas visuais, assim como as estruturas linguísticas, também sinalizam interpretações específicas da 'realidade' e de formas de interação social.

No que concerne à relação entre significado e modos semióticos, Kress e van Leeuwen (2006) argumentam que os significados pertencem à esfera cultural, e, por isso, não estão atrelados a nenhum modo semiótico específico - o que permite que os/as produtores/as de textos multimodais decidam qual o modo semiótico mais conveniente para representar os significados escolhidos. Contudo, os autores ressaltam que quando se escolhe expressar algo por meio de imagens ou de palavras, essa decisão inevitavelmente afeta a produção de significados do que quer que esteja sendo codificado.

Na tentativa de definir do que trata a Gramática do Design Visual, Kress e van Leeuwen (2006: 3) afirmam que primeiramente "ela descreve um recurso social de um determinado grupo, seu 
conhecimento implícito e explícito acerca desse recurso, e seu uso nas práticas do grupo"; em segundo lugar, ela é uma gramática geral o suficiente para englobar pinturas a óleo, layout de revistas, histórias em quadrinhos, diagramas científicos etc. Porém, lembrando que os significados são culturalmente construídos, os autores fazem uma ressalva e afirmam que sua gramática visual serve como recurso para interpretar as representações imagéticas e multimodais da cultura ocidental.

Kress e van Leeuwen inserem seu trabalho sobre representação visual no aparato teórico da semiótica social. Nessa perspectiva, os autores concebem os signos como entidades motivadas - não arbitrárias. Ou seja, para eles, a relação entre significado e significante não é dada, mas construída conforme os interesses dos/as criadores/ as de signos no momento da representação. Segundo os autores:

(...) na semiótica social o signo não é a conjunção pré-existente de um significante e um significado, um signo pronto a ser reconhecido, escolhido e usado como ele é, da maneira como os signos são normalmente considerados 'disponíveis para o uso' na 'semiologia'. Em vez disso, nós focamos no processo de criação de signos, em que o significante (a forma) e o significado são relativamente independentes um do outro até que sejam aproximados pelo criador do signo em um novo signo”. (Kress e van Leeuwen, 2006: 8)

Segundo os autores, um aspecto relevante dessa concepção de criação de signos é que a analogia é um processo de classificação que trata as características consideradas criteriais como senso comum, naturalizando-as - o que pode mascarar relações sociais de poder. Esse é um dos motivos que levam Kress e van Leeuwen a sugerirem que analistas de discurso críticos/as utilizem o conhecimento advindo do estudo da Gramática do Design Visual em suas análises. Em suas palavras:

Analisar a comunicação visual é, ou deveria ser, uma parte importante das disciplinas 'críticas'. Apesar de focarmos, neste livro, na demonstração das regularidades da comunicação visual, em vez de focarmos seus usos ('motivados', isto é, políticos/ideológicos), nós 
vemos todo tipo de imagem como inteiramente inerente ao campo das realizações e instanciações da ideologia, como meio - sempre - para a articulação de posições ideológicas. (Kress \& van Leeuwen, 2006: 14)

Com relação aos textos multimodais, que são cada vez mais comuns nas sociedades contemporâneas, e também constituem área de interesse da ADC, Kress e van Leeuwen ressaltam, primeiramente, que questões relativas a relações de poder e à ideologia também estão presentes nas decisões que os/as produtores/as desses textos fazem ao escolher diferentes modos para representar diferentes aspectos das mensagens que pretendem transmitir. Essas escolhas são influenciadas não apenas pelo potencial semiótico de cada modo, mas também por restrições contextuais - diferentes grupos sociais normalmente possuem interesses divergentes, que podem estar subjacentes às escolhas de determinados modos semióticos em detrimento de outros. Em segundo lugar, os autores (2006: 39) também enfatizam que, diferentemente da concepção semiótica de Barthes (1964), que identifica uma dependência mútua entre textos e imagens, na perspectiva da semiótica social que eles adotam, "o componente visual de um texto é uma mensagem estruturada e independente, conectada com o texto verbal, mas de nenhuma maneira dependente dele, e vice-versa”.

Seguindo a orientação da gramática sistêmica-funcional de Halliday (1994), a gramática visual de Kress e van Leeuwen (2006) também se organiza em três níveis que são realizados simultaneamente, a saber: o nível da representação do mundo e de tudo que há nele (metafunção ideacional), o nível das interações e identidades possíveis (metafunção interacional) e o nível da organização dos elementos que compõem, neste caso, uma imagem de forma a mostrar como esses elementos comunicam-se entre si a fim de criar um todo coerente (metafunção temática).

\section{Imagem como representação}

Em termos de representação do mundo, as imagens podem ser narrativas ou conceituais. Nas representações imagéticas narrativas, 
em vez de identificarmos verbos de ação que determinam quem faz o quê para quem, identificamos vetores - linhas diagonais que unem os/as participantes representados/as; de um lado há o Ator, aquele de quem parte o vetor -, de outro - a Meta, aquele a quem o vetor está direcionado.

As estruturas narrativas são, em sua maioria, agentivas; podendo ser agentivas projetivas ou agentivas não-projetivas. As estruturas agentivas projetivas mentais e as estruturas agentivas projetivas verbais representam o pensamento e a fala, respectivamente, dos/as participantes representados/as, como ocorre em gibis, por exemplo. No caso dos processos mentais, temos o Sensor, o participante de quem parte o balão de pensamento; no caso dos processos verbais, temos o Dizente, o participante de quem parte o balão de diálogo. As estruturas agentivas não-projetivas podem representar uma ação ou uma reação. A ação está relacionada com o que linguisticamente seria representado por meio de verbos de ação, enquanto que a reação está relacionada, exclusivamente, com a ação de olhar. Neste caso, temos o Reator, quem olha, e o Fenômeno, aquilo/aquele/a que é olhado/a.

As estruturas conceituais podem envolver processos classificacionais, analíticos ou simbólicos. Kress e van Leeuwen (2006: 79) definem os processos classificacionais como aqueles que "relacionam os participantes uns com os outros em termos de 'um tipo' de relação, uma taxonomia, pelo menos um dos participantes exercerá o papel de Subordinado em relação a pelo menos um outro participante, o Superordenado”. Fluxogramas e estruturas arbóreas constituem alguns dos exemplos que os autores fornecem para ilustrar os processos classificatórios.

Os processos analíticos não possuem vetores. ${ }^{6}$ Eles relacionam os participantes em termos de parte e todo. $\mathrm{O}$ participante que se refere ao todo é chamado de Portador, o/os participante/s que se referem à/às partes do todo é/são chamado/s de Atributos. No momento em que uma

6. Kress e van Leeuwen (2006: 87-106) fornecem diversos exemplos de estruturas analíticas. Há toda uma complexidade de detalhamento dessas estruturas que não apresentarei neste artigo, mas que vale a pena ser conhecida pelos interessados/as. 
imagem é produzida, a escolha de quais Atributos serão representados e quais serão omitidos pode ressaltar questões ideológicas, uma vez que, segundo Kress e van Leeuwen (2006: 88): "Alguns atributos ou características do/a Portador/a são selecionados/as como criteriais em determinado contexto ou, geralmente, enquanto outros/as são ignorados/as, tratados/as como não-essenciais e irrelevantes”. Em uma foto analítica, um quarto fotografado para uma revista de arquitetura e design, por exemplo, poderia apresentar alguns Atributos como móveis e utensílios, e excluir outros de forma a criar ou representar um estilo. Uma imagem analítica de uma pessoa também ressaltará alguns Atributos - seja a expressão facial, corte de cabelo, vestimenta, acessórios etc., enquanto omitirá outros, considerados menos criteriais, menos definidores, de acordo com o propósito de quem produz a imagem.

Os processos conceituais simbólicos são aqueles que tratam do que um/a participante significa ou é. Eles podem ser de dois tipos: atributivos ou sugestivos. Kress e van Leeuwen (2006: 105) afirmam que os processos atributivos sugestivos têm dois participantes: "o/a participante cujo significado ou identidade é estabelecido na relação, o Portador, e o/a participante que representa o significado ou a identidade, o Atributo Simbólico". Segundo os autores (ibid), os Atributos Simbólicos possuem uma, ou mais de uma, das características abaixo:

1. Eles são ressaltados na representação de uma forma ou de outra; por exemplo, por serem colocados no primeiro plano, através de um tamanho exagerado, por serem especialmente bem iluminados, por serem representados de maneira bem detalhada ou bem focados, ou através de cores ou tons realçados.

2. Eles são apontados por meio de um gesto que não pode ser interpretado como uma ação diferente da ação de 'apontar o atributo simbólico a quem vê a imagem' - aqui também podemos incluir as flechas que podem conectar realizações visuais de participantes com realizações verbais do mesmo participante, ou vice-versa (...).

3. Eles parecem deslocados no todo, de alguma maneira. 
4. Eles são convencionalmente associados com valores simbólicos.

Os processos atributivos sugestivos, por sua vez, possuem apenas um/a participante: o/a Portador/a. O que diferencia os processos atributivos sugestivos dos processos analíticos é que, ao contrário destes, aqueles retiram a ênfase em detalhes, de forma a favorecer o surgimento de uma espécie de 'aura', de 'atmosfera' em torno do/a Portador/a. Os processos atributivos sugestivos não buscam descrever um momento específico, mas a essência do/a Portador/a. Segundo Kress e van Leeuwen (2006: 136), algumas das estratégias usadas pelos/as produtores/as de imagens para conseguir esses efeitos são: mistura de cores, deixando a imagem em um tom azulado, ou dando um brilho dourado à imagem; ou usando iluminação extrema de forma que apenas o esboço do/a Portador/a seja definido.

\section{Imagem como interação}

No nível interacional, a imagem promove a interação entre os participantes nela representados (as pessoas, os lugares e as coisas que ela apresenta) e os participantes interativos (os produtores e consumidores de imagens).

Os significados interativos podem fazer referência ao contato, à distância social e à atitude. Quanto ao contato, quando um/a participante representado/a olha para um/a participante interativo/a, temos uma Demanda; quando o/a participante representado/a não olha para o/a participante interativo/a, temos uma Oferta. $\mathrm{O}$ fato de uma pessoa retratada em uma imagem olhar ou não olhar para o consumidor da imagem é frequentemente explorado em peças publicitárias e em gêneros multimodais midiáticos como as capas de revista. Quando uma pessoa famosa é retratada em uma revista e olha diretamente para os/as leitores/as dessa revista é como se ela exigisse alguma ação ou mesmo alguma emoção dos/as leitores/as da revista. Contudo, quando ela não olha, mas se permite olhar, ela se torna 
um 'objeto' de contemplação, que os/as leitores/as da revista podem observar em detalhes, sem, necessariamente se sentirem impelidos a qualquer tipo de ação ou reação.

No que diz respeito à distância social, os/as produtores/as de uma imagem podem explorar a questão da proximidade entre um/a participante representado/a e um/a participante interativo/a de basicamente de três maneiras. Para estabelecer a distância íntima/ pessoal entre participante representado/a e participante interativo/a, a imagem do/a participante representado/a deve mostrá-lo/la até a altura dos ombros; a distância social é criada quando o/a participante representado/a é fotografado/a até a altura dos joelhos, em média. Finalmente, na distância social, vê-se o/a participante representado/a por inteiro. Essas distâncias se baseiam em códigos sociais do que parece ser uma distância aceitável entre pessoas muito próximas, como amigos e familiares, e entre pessoas estranhas ou que desfrutem de pouca intimidade.

Por fim, a representação imagética da atitude subdivide-se em subjetividade e objetividade. A subjetividade vai indicar envolvimento ou não entre os/as participantes representados/as e interativos/as - a imagem retratada em ângulo frontal sugere envolvimento, é algo que faz parte do nosso mundo, é algo que nos diz respeito; por sua vez, a imagem retratada em ângulo oblíquo sugere distanciamento, não é algo que faz parte do nosso mundo, não é algo que nos diz respeito. A subjetividade também representa relações de poder que podem ser tanto simétricas quanto assimétricas. Se o/a participante representado/a é fotografado/a com ângulo baixo, ele/a é apresentado/a como mais poderoso/a do que o/a participante interativo/a; quando o/a participante representado/a é fotografado/a com ângulo alto, temos a representação do poder do/a participante interativo/a em relação ao/à participante representado/a. Se o/a participante representado/a é fotografado na altura dos olhos, a relação de poder é simétrica entre os/as participantes. Segundo Kress e van Leeuwen (2006: 143) a atitude objetiva é utilizada na representação de diagramas, mapas e tabelas, que podem ser representados com um ângulo frontal ou com um ângulo de cima para baixo, de forma a neutralizar distorções relativas à perspectiva. 
Ainda no nível interacional, representa-se a questão da confiabilidade das mensagens. Uma imagem pode parecer mais ou menos real conforme certas pistas de modalidade que ela apresenta. Como Kress e van Leeuwen (2006) lembram, o termo modalidade vem da Linguística e se refere ao valor de verdade ou credibilidade de enunciados (linguisticamente realizados) acerca do mundo. Um recurso de modalidade linguística é o uso de verbos modais para indicar diversos graus de certeza. As imagens, por sua vez, possuem seus próprios parâmetros de modalidade, dentre os quais Kress e van Leeuwen (ibid) identificam: a) saturação de cores, b) diferenciação de cores, c) modulação de cores, d) contextualização: da ausência de background a um background ricamente detalhado, e) representação, numa escala que vai da abstração à reprodução de detalhes, f) profundidade - da ausência de profundidade à utilização máxima dessa técnica, g) iluminação, em um gradiente de luz e sombras, e, finalmente, h) brilho, variando de apenas dois graus de brilho a vários graus de brilho. Diante de tantas opções para se trabalhar a imagem a fim de deixá-la mais ou menos real, Kress e van Leeuwen afirmam que "a realização da modalidade nas imagens é muito mais complexa e sutilmente graduada do que a realização da modalidade na linguagem” (2006: 163).

\section{Imagem como uma composição coerente}

O nível composicional relaciona os significados representacionais e interacionais da imagem através de três sistemas inter-relacionados: a) valor da informação, b) saliência e c) enquadramento.

O primeiro sistema - valor de informação - pode posicionar os/ as participantes de três maneiras. Primeiramente, os/as participantes podem ser representados/as no eixo horizontal como Dado e Novo: o Dado, posicionado na metade esquerda da página, refere-se à informação tratada como senso comum; o Novo, posicionado na metade direita da página, refere-se à informação nova, aquela que ainda não é consensual. Em segundo lugar, os participantes podem ser representados no eixo vertical como Ideal e Real. Neste caso, a página 
é dividida em: a) uma metade superior, nomeada como Ideal, onde são posicionados/as os/as participantes que representam o desejo, o sonho, as possibilidades, o apelo emocional, e b) uma metade inferior, nomeada como Real, onde são posicionados/as os/as participantes que representam o que é concreto, o que é racional. Em terceiro lugar, os/as participantes podem ocupar uma posição no centro da página, podendo ser ladeados ou circundados por outros/as participantes. Quando temos o valor de informação central, o/a participante que se encontra no centro é considerado/a como o cerne da composição, como aquele/a em relação ao qual os/as outros/as participantes devem ser compreendidos/as.

O segundo sistema - saliência - ressalta alguns elementos da imagem, lidando com sua colocação no foreground ou background, tamanho, contraste de cores e diferenças na definição da imagem. O sistema de saliência correlaciona os/as participantes em um crescendo que parte da saliência mínima para a saliência máxima, ou seja, destaque mínimo a máximo.

O terceiro sistema - enquadramento - utiliza diferentes recursos para sugerir se alguns elementos devem ou não ser interpretados conjuntamente. Linhas divisórias, caixas e diversos outros recursos tipográficos podem separar participantes. Quando não há elementos separando os/as diferentes participantes de uma imagem ou de um texto multimodal, isso demonstra que eles/as podem ser lidos/as em conjunto.

Embora o breve resumo da Gramática do Design Visual apresentado aqui não faça jus ao nível de detalhamento que Kress e van Leeuwen chegam, podemos perceber que essa gramática visual fornece diversos recursos que podem ser muito úteis em análises crítico-discursivas.

\section{Análise da capa da edição 1752 da Veja}

A capa da edição 1752 da Veja, veiculada em 22 de maio de 2002, traz, pela primeira vez, a imagem de Lula naquele ano eleitoral. Nela, lemos a manchete "Por que Lula assusta o mercado", escrita em letras 
brancas e maiúsculas, e colocada na margem inferior esquerda. $\mathrm{Na}$ margem inferior direita, há uma imagem de close up de Lula, olhando para a direita e para cima, contra um plano de fundo vermelho. Em toda a metade superior da página, há um gráfico composto por dois indicadores: um deles se refere à intenção de voto em Lula; o outro, ao risco Brasil.

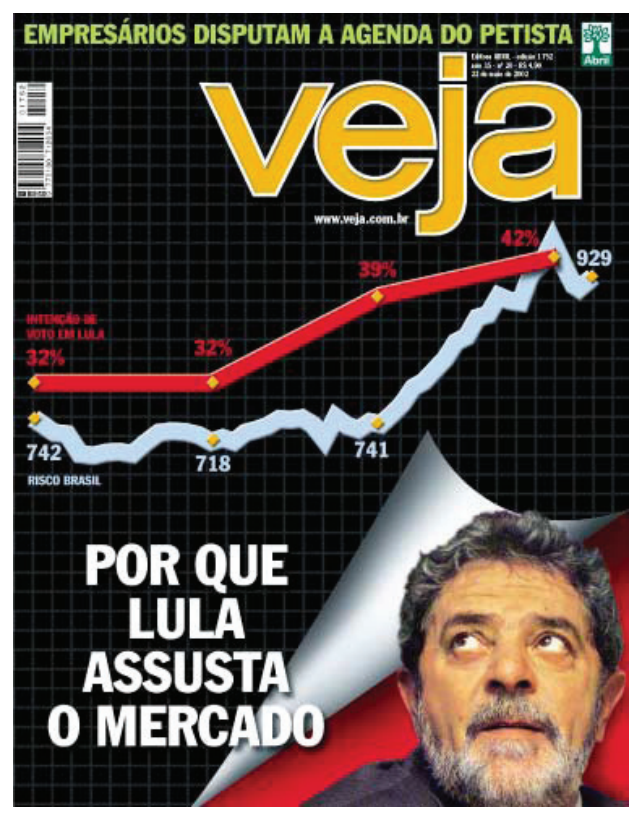

As duas linhas do gráfico encontram-se sobre um plano de fundo preto com quadrados na cor cinza, simulando uma tabela sobre a qual as linhas do gráfico ascendem. Elas partem da margem direita para a margem esquerda: a linha de cima, na cor vermelha, representa a crescente intenção de voto em favor de Lula; a linha de baixo representa o aumento do risco Brasil. Em cada linha há quatro marcações que relacionam a intenção de voto em Lula ao aumento do risco Brasil. No ponto inicial, quando $32 \%$ dos/as entrevistados/as pretendiam votar em Lula, o risco Brasil era de 742 pontos; no ponto seguinte, Lula manteve os 32\%, mas o risco Brasil caiu um pouco para 718 pontos; 
em um terceiro momento, a intenção de votos em Lula passou para $39 \%$, e o risco Brasil obteve uma elevação para 741 pontos. Os últimos dados do gráfico mostram que quando a intenção de votos em Lula atingiu 42\%, o risco Brasil aumentou vertiginosamente, atingindo 929 pontos.

Este último dado leva-nos a perguntar o que pode ter havido para causar tal histeria no mercado. Após um acréscimo de apenas 3\% das intenções de voto em Lula, o mercado reagiu drasticamente elevando em 188 pontos o índice do risco Brasil. Um índice que inicialmente caiu de 742 para 718 pontos, depois se recuperou para 741, e, então, apresentou um crescimento exorbitante, representando quantitativamente e, portanto, racionalmente, a reação dos/ as investidores/as internacionais diante da eleição cada vez mais concreta de Lula. A utilização de números nesta capa da Veja pode ser compreendida, de acordo com Thompson (2009b: 82), como uma estratégia ideológica de legitimação dos dados que os números revelam.

A análise desta capa está organizada de forma a discutir, inicialmente, a maneira como a revista apresenta os/as participantes representados e, em seguida, como ela representa a interação entre esses participantes e os/as leitores/as. Em um terceiro momento, veremos como os vários elementos que compõem esta capa da Veja se unem em um todo coerente e responsável por efeitos de sentido direcionados aos/às consumidores/as da revista.

O primeiro participante representado a ser comentado nesta análise é o gráfico - um participante que é retratado por meio de um processo analítico classificacional temporal. Embora as datas em que foram colhidos os dados desse gráfico não tenham sido explicitadas, há o pressuposto de que os dados seguem uma sequência temporal. O gráfico como um todo é o Portador e os dados são seus Atributos - as partes do todo. No gráfico que aparece nessa capa da Veja, os/ as produtores/as consideraram essencial deixar claro a que se refere cada linha do mesmo, a saber: a linha vermelha refere-se aos votos em Lula; a linha cinza, ao risco Brasil. Cada uma das linhas contém quatro Atributos, correspondendo às porcentagens que representam 
as intenções de votos em Lula e os números do risco Brasil, respectivamente.

Calculado pelo banco de investimentos norte-americano JP Morgan, o risco país mede o provável nível de risco ou desconfiança de investidores internacionais que planejam aplicar em títulos em países emergentes nos quatro cantos do globo. Nas Américas, calculase o risco país do México, da Argentina, da Venezuela, da Colômbia, do Peru, do Equador, e do Brasil. Embora haja controvérsias quanto à confiabilidade do risco país, esse índice é colocado na capa da Veja como uma 'vontade de verdade', como diria Foucault (2006: 16). Quando a Veja traz na capa os indicadores de crescimento da intenção de voto em Lula condicionando o aumento do risco país, ela apresenta essa informação como fato per si. A revista não menciona quais agências colheram os dados nem a que datas eles correspondem. Essas informações apenas serão disponibilizadas posteriormente, e separadamente, em duas matérias que a revista dedica à manchete da capa.

Na matéria "Empresários na agenda de Lula", assinada por Alexandre Secco e Maurício Lima, temos a informação sobre o instituto que pesquisou a intenção de votos nos candidatos à presidência e em quais datas. Na matéria "O que eles temem em Lula", assinada por Eurípedes Alcântara, temos a informação sobre qual instituto pesquisou a questão do risco Brasil e em quais datas. A matéria de Secco e Lima esclarece que a pesquisa acerca das intenções de voto dos/as brasileiros/as nos candidatos à presidência da república foi feita pelo Instituto Vox Populi em quatro momentos específicos de março a maio de 2002, a saber: a) 10 a 13 de março; b) 27 e 28 de março; c) 19 e 20 de abril, e d) 13 de maio. Nessas datas, o Vox Populi pesquisou as intenções de voto não apenas em Lula, mas também em Serra, Garotinho e Ciro.

$\mathrm{O}$ artigo de Alcântara permite-nos tomar conhecimento de que a pesquisa acerca do risco país foi conduzida pelo Banco JP Morgan também entre março e maio - nas seguintes datas: a) 11 de março; b) 28 de março; c) 19 de abril e d) 17 de maio. O risco país foi calculado apenas em relação a Lula. Essas informações ficam claras para os/as 
leitores/as que comprarem a revista e lerem as matérias mencionadas acima; entretanto, para aqueles/as que apenas entrarem em contato com a capa da revista em uma banca de revistas, por exemplo, não há como saber que esses dados foram colhidos separadamente por duas instituições distintas. A forma como a capa une as informações colhidas em pesquisas distintas torna possível uma associação mais instantânea, mais imediata entre o que cada linha do gráfico mostra, e isso poderia ser ideologicamente muito conveniente em tempos eleitorais.

Os/as produtores/as da capa representaram o gráfico aparentemente pressupondo que os/as leitores/as familiarizados/ as com gráficos utilizariam seus conhecimentos prévios para inferir que os dados das duas linhas estavam sendo tomados em termos comparativos, e não poderiam, portanto, terem sido colhidos em datas muito diferentes. Além disso, as distâncias entre um Atributo e outro de cada linha são semelhantes, reforçando a ideia de que foram obtidos se não na mesma data, em datas próximas. Mas, por que as datas não são colocadas no gráfico? Por que as fontes não são mencionadas? A resposta mais provável para essas perguntas diz respeito ao fator foco. Quanto mais informação o gráfico mostrasse, mais a atenção dos/ as leitores/as seria desviada do que, nesse caso, parecia ser essencial: associar o crescimento da intenção de votos em Lula ao crescimento do risco Brasil.

No que diz respeito à representação da imagem da Lula, temos uma estrutura narrativa. Sabemos disso porque podemos imaginar um vetor - uma linha que parte dos olhos de Lula em direção ao gráfico acima. Temos, então, dois participantes unidos pelo vetor: de um lado - Lula, do outro - o gráfico. Dessa forma, Lula é representado como o Experienciador e o gráfico como o Fenômeno. Enquanto no modo verbal dessa capa multimodal - na manchete - o sintagma Lula desempenha um processo transacional relacionado a uma ação: ele "assusta o mercado"; no modo imagético, Lula desempenha um processo relacionado a uma reação: ele reage ao que vê. O que está em jogo nesta estrutura narrativa é um processo reacional, nesse caso o ato de olhar para. Há um Reator: Lula, que reage ao que vê - o 
Fenômeno. Lula é o participante ativo no processo reacional; é do olhar dele que surge o vetor que o ligará ao gráfico - o participante passivo que constitui o objeto do olhar do Reator.

Nesta capa, Lula reage ao gráfico, que associa os indicadores de intenção de voto em sua candidatura à presidência com aqueles que dizem respeito ao crescimento do risco Brasil. A foto obviamente não foi tirada enquanto ele olhava realmente para tal gráfico. Entretanto, como imagem escolhida entre tantas a que imaginamos que os/as produtores/as da capa da revista tenham acesso, vemos que a testa enrugada de Lula demonstra preocupação. Assim como o gráfico chamou a atenção de Lula, preocupando-o, ele também chama a atenção dos/as leitores/as. De fato, o olhar de Lula parece guiar o olhar dos/as leitores/as para o gráfico. Talvez seja essa a principal função da imagem de Lula - levar os/as leitores/as a se aterem aos dados que o gráfico apresenta. Se há razão para Lula estar preocupado, também é natural que os/as leitores/as receiem os dados que os gráficos revelam.

No que concerne à esfera da representação da interação, que posiciona aqueles que vêem a imagem em relação à imagem em si, a imagem de Lula escolhida para essa capa é uma Oferta. Nela, Lula não olha diretamente para os/as leitores/as da revista; ele se deixa olhar, segundo Kress e van Leeuwen (2006: 119), como "um item de informação, um objeto de contemplação", que não demanda uma resposta das pessoas que vêem a imagem. Nesse tipo de imagem não se espera que os/as leitores/as se engajem com o participante retratado: não se espera que os/as leitores/as tenham empatia por Lula, ou se identifiquem de alguma forma com ele. Este fato, entretanto, é contraditório se levarmos em conta que a imagem de Lula está em close up - que equivale à distância social que se mantém de alguém íntimo, o que poderia aumentar as chances de sentirmos empatia por ele.

Essa contradição, contudo, pode ser minimizada se aceitarmos que além de sentirmos empatia no que concerne às atitudes, ações e experiências daqueles que nos são íntimos, muitas vezes, essa mesma intimidade também nos permite condenar suas atitudes e ações de forma mais contundente. Lula é uma personalidade política, ele não 
é um familiar ou amigo íntimo dos/as leitores/as. Porém, quando a Veja representa Lula como socialmente próximo dos/as leitores/as, ela abre um espaço para que estes/as estabeleçam uma relação emotiva e pessoal com ele, podendo julgar seus atos e perguntarem-se por que ele assusta o mercado.

No que diz respeito à composição desta capa como um todo, vemos que ela foi organizada no eixo vertical: Ideal/Real. No lugar do Ideal, ou seja: na parte superior da página, há as linhas do gráfico que correm de um lado ao outro da página. No lugar do Real, ou seja: a parte inferior da página, há a manchete principal, à direita, e a foto de Lula, à esquerda. A parte superior e a parte inferior da imagem são simbolicamente separadas pela segunda linha do gráfico, que divide a página ao meio.

Focando agora apenas os elementos que se encontram no lugar do Real, podemos ver que a manchete principal foi posicionada à esquerda, sendo representada como o elemento Dado. $\mathrm{O}$ modo semiótico escolhido pelos/as produtores/as da capa, como normalmente acontece em nossa cultura no que diz respeito a manchetes de jornais e revistas, foi o modo verbal. Utilizando os recursos tipográficos disponíveis, os/as produtores/as da capa optaram por utilizar letras brancas, em negrito, todas maiúsculas. As letras brancas da manchete contrastam com o plano de fundo negro como se expressassem um fato "preto no branco", inconfundível e tão convincente quanto os números do gráfico. Além disso, como a manchete ocupa apenas o quadrado que corresponde à margem inferior esquerda da página, ela foi estruturada em forma de coluna, isolando cada elemento da frase da seguinte maneira: 'por que' vem acima de 'Lula', que vem acima de 'assusta', que vem acima de 'o mercado'. Essa organização do texto salienta os diferentes elementos que compõem a manchete principal, potencialmente aumentando o impacto da manchete como um todo.

É importante lembrar que em mídia dificilmente se produz algo casualmente. Uma questão a ser ressaltada é que a revista representa Lula como Ator do processo 'assustar' tendo como Meta o mercado. Os/As produtores/as da capa poderiam ter optado por uma infinidade de outras estruturas léxico-gramaticais, mas decidiram-se pela 
manchete apresentada: uma manchete que diz claramente quem faz o quê, ressaltando a agência de Lula no que diz respeito a um fato que desfavorece sua candidatura: ele assusta o mercado. A naturalização do fato de que Lula assusta o mercado é reforçada pelo posicionamento da manchete no lugar do Dado: do que é senso comum, do que não é questionável. Por 'não questionável' aqui, entenda-se que a mensagem foi codificada de forma a transmitir esse sentido; o que não significa que todos/as os/as leitores/as concordarão com essa codificação, já que segundo Thompson (2009a), o trabalho de recepção de mensagens é ativo e pode ser criativo em relação à codificação da mensagem.

Ainda no plano do Real, o elemento que se encontra no quadrante inferior direito da página é uma foto de Lula em close up, de frente para os/as leitores/as, com o rosto levemente voltado para a direita, olhando para cima e para a direita como se pudesse ver o gráfico que se encontra na metade superior da página. Colocando a imagem de Lula no espaço reservado ao Novo, a Veja trata Lula como ainda não consensual, como o que é problemático, como o que deve ser considerado com atenção, como o que ainda não foi naturalizado. Lula ainda não era o presidente do Brasil, mas se ele viesse a ser e como o gráfico mostra, havia uma grande probabilidade de isso acontecer - a economia brasileira poderia ser afetada. Seria aquele o cenário que o povo brasileiro desejaria para o Brasil? Provavelmente, não. A colocação da imagem de Lula no lugar do Novo constrói uma mensagem subliminar de receio e dúvida.

Em resumo, posicionadas no lugar do Real, a manchete principal e a imagem de Lula, aparecendo como que de surpresa por debaixo da extremidade da folha que se ergue, representam como concreto o fato de Lula assustar o mercado. Lembremos que, enquanto o Real tem uma função mais informativa e prática, o Ideal, onde se encontra o gráfico associando intenções de voto em Lula ao crescimento do risco Brasil, tem uma função mais emotiva, mais apelativa. O gráfico aparece no lugar do Ideal como uma previsão assustadora do que poderia vir a significar a eleição de Lula.

Finalmente, não se pode deixar de observar como a cor vermelha é utilizada nessa capa. Para Kress e van Leeuwen (2001), quando uma 
cor é usada como um signo semiótico motivado seu significado e seu significante não estão previamente atrelados um ao outro. A relação entre significado e significante é construída pelos/as produtores/as da capa para trazer à tona significados que sejam pertinentes a um determinado contexto. No contexto desta capa, o vermelho, que aparece como plano de fundo da imagem de Lula e em uma das linhas do gráfico, codifica a cor do PT e tudo o que o partido representa: seu ideário, as ações e atitudes de seus membros, seu passado histórico, seu plano de governo.

Contudo, pode-se dizer que o vermelho também agrega coesão à composição do todo desta capa multimodal, codificando a ideia de cautela. Em primeiro lugar, porque o vermelho aparece no lugar do Novo - do que é problemático. Em segundo lugar, porque o vermelho da cautela nos remete ao gráfico que representa uma realidade nada favorável para o Brasil enquanto país emergente. Assim como no trânsito paramos diante de um sinal vermelho, a Veja parecia sugerir que a população parasse e atentasse para o que poderia significar a eleição de Lula, estruturando uma mensagem tanto para aqueles/ as que pretendessem votar em Lula como para aqueles/as que não pretendessem votar nele. Os/As primeiros/as poderiam vir a rever seus votos; os/as segundos/as poderiam ratificar suas preocupações quanto à possibilidade de Lula ser eleito. Afinal de contas, se Lula assusta, seria prudente ter cautela.

\section{Algumas considerações finais}

A análise da capa da edição 1752 da Veja apresentada neste artigo buscou explorar o potencial dos recursos fornecidos pela Gramática do Design Visual em um exercício de análise de discurso crítica. A análise demonstrou que esta capa trouxe a representação do discurso do medo tanto por meio do modo verbal quanto por meio do modo visual. No plano verbal, os/as produtores/as dessa capa representaram o discurso do medo atribuindo a Lula a agência do processo 'assustar' o mercado. Já no plano visual, o discurso do medo 
foi codificado, a) no gráfico que associava o aumento do risco Brasil ao aumento da intenção de votos em Lula, b) na agência atribuída a Lula como Reator conectado ao gráfico, enquanto Fenômeno, por um vetor, e c) na imagem de Lula surgindo por debaixo da ponta da folha que se ergue.

Representar o discurso do medo, associando-o a um político que é candidato à presidência do país, em um ano eleitoral, potencialmente seria prejudicial à imagem pública e, portanto, ao 'capital simbólico' (Thompson, 2009a; Bourdieu, 1989) desse político. As pessoas votam nos políticos em quem confiam. É a imagem honrada e digna de confiança que os políticos conseguem construir para si mesmos que constitui o maior capital simbólico de que dispõem. Por isso, a perda de capital simbólico é especialmente danosa para os políticos, que dele precisam para se elegerem e colocarem em prática seu poder político.

Quando a Veja representa o discurso do medo tanto no modo verbal quanto no modo visual, ela enfatiza o perigo que uma eventual eleição do candidato do PT poderia significar para o país. Essa capa não faz nenhuma menção à mudança empreendida por Lula, em seu discurso, em suas atitudes e em suas ações, nas eleições de 2002. O Lula de 2002 já não parecia tão "vermelho" como em eleições anteriores.

A revista poderia ter trazido, na capa da edição 1752, a manchete: "Empresários na agenda de Lula" - título de uma das matérias dessa mesma edição. Nessa matéria, lê-se que a "agenda de Lula para os próximos meses registra compromissos com banqueiros, industriais e fazendeiros (...) As principais câmaras de comércio exterior (...) estão preparando a reunião conjunta para ouvir as propostas de Lula. Tratase de uma mudança notável”.

Conforme a perspectiva do Realismo Crítico adotada pela ADC, podemos compreender a capa da edição 1752 da Veja como um evento discursivo que diante de todo um potencial de abordagem de um determinado evento social, optou por realizar uma representação que desfavoreceria o candidato do PT. Considerando a parcialidade nãodeclarada da Veja, uma possibilidade de aprofundamento da análise da capa da Veja apresentada neste artigo seria investigar quais possíveis 
motivações político-econômicas teriam levado a Veja a representar Lula, tão enfaticamente, como aquele que assusta, como aquele que é temido.

Todos os comentários que os recursos da Gramática do Design Visual me possibilitaram fazer ao longo da análise da capa da edição 1752 da Veja apontam também para o potencial pedagógico desses recursos e para a relevância de utilizá-los em práticas de leitura de textos midiáticos multimodais. A Análise de Discurso Crítica preocupa-se em emancipar os sujeitos desvendando construções ideológicas ocultas em textos. Nesse contexto, os recursos da Gramática do Design Visual parecem ser bastante úteis para trazer à superfície tais construções, podendo vir a interessar não apenas a pesquisadores/as das áreas de mídia e de análise de discurso, mas também a pesquisadores/as interessados/as em aprofundar questões de letramento crítico.

Recebido em: 24/08/2011

Aprovado em: 23/09/2011 alecfernandes1@hotmail.com]

\section{Referências bibliográficas}

BASKHAR, R.; LAWSON, T. Introduction: basic texts and developments. In: ARCHER, M.; BHASKAR, R.; COLLIER, A.; LAWSON, T.; NORRIE, A. Critical Realism: essential readings. London: Routledge, 2007, p. 3-15.

BASKHAR, R. Scientific realism and human emancipation. London: Routledge, 2009.

BASKHAR, R. Societies. In: ARCHER, M.; BHASKAR, R.; COLLIER, A.; LAWSON, T.; NORRIE, A. Critical Realism: essential readings. London: Routledge, 2007, p. 206-257.

BLOOR, T.; BLOOR, M. The functional analysis of English: A Hallidayan Approach. Bristol: Arnold, 1995. 
BOURDIEU, P. Language and symbolic power. Translated by Gino Raymond; Matthew Adamson. $7^{\text {th }}$ printing. Cambridge, MA: Harvard University Press, 2003.

BUTT, D. et al. Using Functional Grammar: an explorer's guide. Sydney: Macquarie University, 1998.

CHOULIARAKI, L.; FAIRCLOUGH, N. Discourse in late modernity: rethinking critical discourse analysis. Edinburgh: Edinburgh University Press, 1999.

EGGINS, S. An Introduction to systemic functional linguistics. London: Pinter, 1994.

FAIRCLOUGH, N. Analysing Discourse: textual analysis for social research. New York: Routledge, 2003.

FAIRCLOUGH, N. Discurso e mudança social. Coordenadora da tradução: Izabel Magalhães. Brasília: Universidade de Brasília, 2001.

FAIRCLOUGH, N. Critical discourse analysis. New York: Longman, 1995.

FAIRCLOUGH, N. Media discourse. New York: Edward Arnold, 1995.

FAIRCLOUGH, N. Discourse and social change. Cambridge: Polity Press, 1994.

FAIRCLOUGH, N. Language and power. New York: Longman, 1993.

FOUCAULT, M. A ordem do discurso. São Paulo: Edições Loyola, 2006.

GIDDENS, A. A vida em uma sociedade pós-tradicional. In: GIDDENS, A.; BECK, U.; LASH, S. Modernização reflexiva: política, tradição e estética na ordem social moderna. Tradução: Magda Lopes. São Paulo: UNESP, 1997, p. $73-134$

GIDDENS, A. As consequências da modernidade. Tradução: Raul Fiker. São Paulo: UNESP, 1991.

HALLIDAY, M. A. K. An Introduction to Functional Grammar. 2. ed. London: Arnold, 1994.

HALLIDAY, M. A. K. Language as Social Semiotic: The social interpretation of language and meaning. 8. ed. London: Arnold, 1993.

HARVEY, D. Condição pós-moderna: uma pesquisa sobre as origens da mudança cultural. Tradução: Adail Sobral; Maria Stela Gonçalves. 18. ed. São Paulo, Edições Loyola, 2009. 
HARVEY, D. O Neoliberalismo: história e implicações. Tradução: Adail Sobral; Maria Stela Gonçalves. São Paulo: Edições Loyola, 2005.

HERNANDES, N. A mídia e seus truques. São Paulo: Contexto, 2006.

JOHNSON, S.; PRIJATEL, P. The magazine from cover to cover. 2. ed. Oxford: Oxford University Press, 2007.

KRESS, G.; VAN LEEUWEN, T. Reading Images: the grammar of visual design. 2. ed. London: Routledge, 2006.

KRESS, G.; VAN LEEUWEN, T. Multimodal Discourse: the modes and media of contemporary communication. London: Edward Arnold, 2001.

KRESS, G. Multimodality, multimedia, and genre. In: HANDA, Carolyn. Visual rhetoric in a digital world: a critical sourcebook. NewYork: St. Martin's, 2004.

KRESS, G. Linguistic processes in sociocultural practices. Oxford: Oxford University Press, 1989.

LASH, S. A reflexividade e seus duplos: estrutura, estética, comunidade. In: GIDDENS, A. et al. Modernização reflexiva: política, tradição e estética na ordem social moderna. Tradução: Magda Lopes. São Paulo: UNESP, 1997, p. 135-206.

LEVINE, P.; SCOLLON, R. Discourse and technology: multimodal discourse analysis. Washington, D.C: Georgetown University Press, 2004.

MAGALHÃES, I. Introdução: a análise de discurso crítica. Disponível em:http://www.scielo.br/scielo.php?script=sci_arttext\&pid =S0102-44502005000300002. Acesso em: 25/01/11.

MCLOUGHLIN, L. The language of magazines. New York: Routledge, 2006.

RAMALHO, V. Análise de Discurso Crítica e Realismo Crítico. Princípios para uma abordagem crítica explanatória do discurso. Disponível em: http://www. uff.br/iacr/ArtigosPDF/7T.pdf. Acesso em: 10/07/10.

RESENDE, V. M. Análise de Discurso Crítica e Realismo Crítico: implicações interdisciplinares. Campinas, SP: Pontes, 2009.

RESEndE, V. M.; RAMALHO, V. Análise de Discurso Crítica. São Paulo: Contexto, 2006.

SAMUELS, D. A democracia brasileira sob o governo de Lula e do PT. In: ANGELO, Vitor A. de; VILA, Marco A. (Orgs.). O partido dos trabalhadores 
e a política brasileira (1980-2006): uma história revisitada. São Carlos, SP: EDUFSCAR, 2009, p.239-270.

SCALZO, M. Jornalismo de revista. São Paulo: Contexto, 2003.

SILVA, A. O. Nem reforma nem revolução: a estrela é branca. In: ANGELO, V. A.; VILA, M. A. (Orgs.). O partido dos trabalhadores e a política brasileira (1980-2006): uma história revisitada. São Carlos, SP: EDUFSCAR, 2009, p.13-34.

TALBOT, M. Media Discourse: representation and interaction. Edinburgh: Edinburgh University Press, 2007.

THOMPSON, J. B. A mídia e a modernidade: uma teoria social da mídia. Tradução de Wagner de Oliveira Brandão. 11. ed. Petrópolis, Rio de Janeiro: Vozes, 2009a.

THOMPSON, J. B. Ideologia e cultura moderna: teoria social crítica na era dos meios de comunicação de massa. Tradução do Grupo de Estudos sobre Ideologia, comunicação e representações sociais da pós-graduação do Instituto de Psicologia da PURCS. 8. ed. Petrópolis, Rio de Janeiro: Vozes, 2009b.

Van Leeuwen, T. Discourse and practice: new tools for Critical Discourse Analysis. Oxford: Oxford University Press, 2008.

Van Leeuwen, T. Ten reasons why linguists should pay attention to visual communication. IN: LEVINE, P.; SCOLLON, R. (eds.). Discourse and technology: multimodal discourse analysis. Washington, D.C: Georgetown University Press, 2004. 